\title{
Research on Construction of International Logistics Center Relying on Silk Road Economic Belt
}

\author{
Yuqin Wang \\ Xi'an International University, Xi'an Shaanxi, 710077, China
}

Keywords: Silk Road, Economic Belt, International Logistics, Construction, Measures

\begin{abstract}
A key factor affecting the economic growth is the road transportation cost. If the transportation cost can be cut down, it can bring quite large economic flow space for logistics and population flow, further to promote the fast economic growth. It also means that, the core factor affecting the regional economic growth is the logistics. Therefore, China should consider how to construct a logistics center with low cost and high efficiency while constructing the new silk road economic belt currently. Based on that, this paper starts from the logistics development significance of silk road economic belt, specifies the basic thoughts of constructing the international logistics center on the silk road economic belt, further to conclude the concrete measures of constructing the international logistics center.
\end{abstract}

\section{Introduction}

In order to create the foreign and domestic cooperative environment for silk road and strengthen China's radiation of industrial layout and economic development ability to the west areas, combined with the current modern industrial pattern, it makes innovations of the supply chain management, develop new development mode and take advantage of concentrated development zones and provincial capitals of economic development along the silk road belt, create strategical supporting nodes clustered by many industries, which just refer to the logistics band of silk road economic belt. Meanwhile, it needs to take advantage of highway, railway and airline(of which, it also includes the service function of comprehensive transportation hub), so as to reduce the logistics cost of products, promote the international competence of industries and create the new mode of western development "stringing the points together by channels, concentrating the hub by points, promoting the development by hub”.

\section{Important Significance of Constructing International Logistics Center}

Currently, confronted by the competition of large maritime volume, more and more industrial development need to utilize the land passage to make economic relation, but the development of land passage has certain limits, which have also hindered economic development among all nations and economic cities. The international logistics center of silk road economic belt is majorly the transportation channel dominated by important logistics join nodes and hub nodes. Compared to the transportation channels in the past, the biggest advantage lies in diversified transportation service. As the operation function of logistics service with whole-process trade and economic belt production, it is the modern service system mostly demanded by the current industrial development and organization, which not only has low transportation cost, but also good transportation efficiency. To speed up the construction of international logistics center of logistics hub cities along the silk road, the significance is not only embodied in the industrial layout integrated of modern logistics and industry, but also embodied in the changes of international industrial layout with cost advantage and efficiency advantage under the current logistics service system.

Firstly, an important precondition of expanding the silk road economy is the development of modern logistics system. The construction of silk road economic belt mainly lies in letting the commodities of west-radiated regions and economic belt to circulate freely, further to realize the purpose of sharing resources. The silk road strides over quite broad areas, thus the transportation cost is relatively quite high. Due to the low cost of modern maritime transportation and large volume, in 
order to develop the product economy by developing the land passage, it must clear the obstacles of logistics communication between countries and cities firstly. By taking advantage of the current modern logistics service system, it needs to give full play of logistics operation efficiency and advantage of comprehensive service cost, and expand the regions to develop into Eurasian continent by innovating the transportation infrastructure and service development mode. In addition, it can take advantage of enterprises' logistics supply service system, logistics information platform, logistics hub nodes and logistics service organizations, construct transnational logistics channel and improve the role of logistics service system in the industrial chain of silk road economic belt.

Secondly, the key to promote the integrated development of international and domestic economy is also the modern logistics system. By constructing the comprehensive transportation thoroughfare of silk road and the modern logistics system of hub cities along the silk road economic belt, it can improve the allocating effects of excellent resources and free mobility of commercial trade and production factors from different continents, countries and regions, so as to realize the role of market economy in the resource allocation. Besides, it can strengthen the economic relationship and industrial development among different regions, promote industrial division and cooperation, further to realize the economic integration of hub cities along the silk road economic belt. Especially in the economic cities with developed logistics service system, with the constant expansion of industrial development, it needs to stick to industrial cooperation. Meanwhile, it should make reasonable reform of the current urban resources and development demand mode, re-cultivate new development demand mode and promote the economic integration development of international and domestic hub cities.

Thirdly, it is the modern logistic system that guarantees the economic industrial chain development and regional expansion of hub cities along the silk road economic belt. Relying on the close relationship between the modern logistics service and manufacturing industries, it can create a good environment for the development of logistics service system of silk road economic belt. It needs to take advantage of logistics service system's international radiating ability with high efficiency and low cost, realize the upgrading and transition of the service industry, manufacturing industry, sales industry of the hub cities along the economic belt, further to promote the development of economic industry of hub cities. Therefore, the biggest role of the modern service system lies in guaranteeing the economic development of hub cities along the silk road economic belt.

\section{Primary Condition for Construction of International Logistics Center}

During the development of new silk road economic belt, the transportation construction is most important. Moreover, the precondition to construct the international logistics center is the convenient condition. Xi Jinping, General Secretary of China, ever said that: to connect the transportation of South Asia, West Asia and East Asia together, it needs to open the transportation line from the Pacific Ocean to the Baltic Sea, further to reinforce the connection among roads. The transportation efficiency of land is lower than that of land and sea. The national road construction department has already specifically put forward that, the railway construction must become the major transportation route from the Pacific Ocean to the Baltic Sea. Currently, "Wuhan-Xinjiang-Europe” Freight Railway and "Sichuan-Europe" Express Railway have already been successfully built. In addition, Shanxi $\mathrm{Xi}$ 'an has already gradually developed into the major city of goods distribution center in China and Central Asia.

Through constructing and improving the transportation infrastructures, it cannot only improve the transportation capacity of all provinces along the belt, but also solve the transportation barriers, improve the freight transportation capacity and speed up the development pace of international standard for highway and railway technology. By analyzing the survey data, it can be concluded that, the freight volume of Gansu has been improved by about 30\% than before, that of Shanxi has been increased by $20 \%$. Freight volume of Jiangsu and Fujian has also been increased by $10 \%$. Freight transportation capacity and volume in western areas has also been increased by nearly $20 \%$. All the data can prove the improvement of transportation infrastructures, which not only promote the freight 
transportation capacity of all provinces along the belt, but also fully embody the advantage to construct the international logistics center.

\section{Major Thoughts of Constructing and Developing International Logistics Center along the Silk Road Economic Belt}

Developing High-Efficient International Logistics Channel. So far, Hohhot, the provincial capital of Inner Mongolia, has already opened 9 international container through trains, including Xi'an-Xinzhu-Europe Chang'an International Freight Train, Suzhou-Manzhouli-Europe Container Train, Wuhan-Xinjiang-Europe Freight Train, Foxconn International Container Train, BeijingHamburg Container Demonstration Train, Chongqing-Duisburg Container Train, Sichuan-Europe Through Container Train, Zhengzhou-Xinjiang-Europe International Freight Train.

Some hub cities related to the silk road economic belt are trying to open Eurasian railway container international freight train to all European countries. However, some cities with quite good economic development have been confronted by many problems, including Xi'an, Wuhan, Chongqing, Zhengzhou, etc. International transportation railways opened by these cities have quite low deficiencies. Therefore, it needs to create logistics service system and logistics common transportation platform to clear the economic belt, so as to integrate the international railway container transportation resources of all key cities, further to satisfy the normalization, logistics and scale of Eurasian railway container freight train. Besides, it can set up the freight logistics back-and-forth mechanism between Asia and Europe, complete the requirement of transforming from transportation corridor to logistics corridor, so as to realize the purpose of creating an international logistics transportation corridor with low cost and high efficiency.

Establishing International Logistics Hub Base. Establishment of Eurasian international logistics base has extremely high requirements of the logistics hub. The logistics must be high efficient and convenient, with quite low cost. Therefore, it needs to encourage key cities of the economic belt to give full play of advantages of railway container central station, comprehensive bonded zone, highway port and air harbor. It aims at solving the problem that central cities of economic belt compete for the international logistics hub position aimlessly. By taking advantage of the central cities' logistics hub, it can solve all kinds of problems among all cities' logistics hub, including resource share, information service, communication cooperation, logistics transportation. Targeted at the transportation development requirements supporting the hub cities, it can create an operation platform with quite strong radiating ability, professional operation and comprehensive service function, so as to improve the position of central cities' logistics hub in the international logistics hub along the silk road economic belt, and then comprehensively improve the speed to develop the international logistics service industry.

Improving the Logistic Service Efficiency of the Economic Belt. According to the requirements of central cities' logistics hub, it should positively improve the current service environment of logistics service and integrate the logistics resources of road transportation to the west, give full play to the logistics service during the construction of logistics service mechanism of the silk road economic belt. In addition, it should improve the cooperative level among enterprises, strengthen the enterprises' ability of labor-division and cooperation, which has played a quite important role in improving the logistics service efficiency of the economic belt. Because the Silk Road Economic Belt covers quite broad areas, which results in the situation that it is hard to carry out cooperation or coordination among some interest-related transportation organizations. Therefore, it must strengthen the logistics resource coordination and integration among regions, give full play to the tole of governmental agencies in the logistics service organization, so as to realize the purpose of market integration, solve the obstacles hindering cooperation and win-win and promote the development of labor-division. 


\section{Measures for Industrial Development of the Silk Road Economic Belt and Construction of International Logistics Center}

Coordinating the Planning and Construction. Business Planning of logistics of the Silk Road Economic Belt takes "high-standard, high-starting point, high-efficiency" as the core content. In the layer of economic development, according to the planning requirement of locating development orientation, specifying the assigned task and clearing the development of economic belt, it is mainly dominated by national strategy of westward opening, so as to improve the speed to develop the industry along the Silk Road Economic Belt. Besides, it should specify the role of logistics hub base in the measure of westward development, construct the "three-high" international logistics hub integrated of low cost, high efficiency and powerful resource integrating ability, create an integrated and orderly international logistics service site, improve the current network management system of transportation corridor, promote the development of logistics system of the Silk Road Economic Belt.

Setting up the Coordination Mechanism. The Silk Road Economic Belt contains a lot of provinces and cities. In order to create an unified logistics service development market and perfect westward radiating logistics service system, it must combine the international commerce, international logistics commerce and transit logistics commerce together, so as to create a long-term mechanism suitable for the logistics development of economic cities. Therefore, it is the priority among priorities to positively set up an organization managing the logistics service of the Silk Road Economic Belt.

Implementing the Program of Attracting Investments. In order to promote the cooperation during the process of constructing the logistics system of the Silk Road Economic Belt, it must take full advantage of the atmosphere conforming the industrial development created by the logistics service environment, integrate resource advantages of all central cities along the economic belt and endowments suitable for the industrial development, increase the competence of logistics resources in the international logistics system, take full advantage of all central cities' industrial advantages to create logistics hub cities dominated by industrial development. Based on that, related departments of China or related regional units should positively publish some encouraging policies, so as to promote the development of central cities and create the development path dominated by industrial clustering. Meanwhile, combined with the current situations, it should attract investments, specify the mode and conception of program of attracting investments, and then broaden the scope of industrial development.

Making Innovations of Development Policies. As all central cities involved in the Silk Road Economic Belt, they need to combine with the requirements of logistics service system along the belt and international regional logistics hub, make innovations of the current logistics development policies, improve some policies and thinking modes that mainly rely on financial policies, land preference policies and tax policies, explore new policies that can promote the construction of logistics service industrial chain and industrial centralized development, further to improve the positions of all central cities along the Silk Road Economic Belt in the foreign and domestic economy and industrial competition development. Policy innovations mainly include the policies of logistics system construction dominated by international logistics resources, policies of free trade zone centering on negative list management, policies taking the cultivation of freight commerce development capacity with international competence as the precondition, etc.

\section{Conclusion}

In conclusion, with constantly improved international position of China, Chinese international trade position has also been improved. Especially with the formation of The New Silk Road Economic Belt, the logistics industry has correspondingly got rapid development. To construct the international logistics center along the New Silk Road Economic Belt, it is conductive for the father development of China's international trade. In addition, to a great extent, it can change the development level of logistics hub cities along the economic belt and make contributions to the improvement of China's economic construction. 


\section{Acknowledgments}

This paper is the scientific research project of Shanxi Provincial Department of Education, Serial No.15JK2130

\section{References}

[1] Song Yu, Tan Renchao. Strategical Conception of Constructing "The Silk Road Economic Belt" and Opportunities of Shanxi. Journal of Xi'an University of Finance And Economics, 2015,(02):73-78.

[2] Zhao Hui. Explorations on the Development Status of International Logistics under the Low-carbon Economic Circumstance and Countermeasures for Improvement. China Business(Economic Theory Research), 2015,(12):63-64.

[3] Li Wenzeng, Feng Pan, Li La. Give the Play to Tianjin Port in Economic Development Strategy of China’s New Silk Road. Port Economy, 2014,(03):43-46.

[4] Li Zhongmin, Yu Qingyan. Research on Logistics Promoting the Spatial Heterogeneity of Economic Growth--taking “New Silk Road” Economic Belt as an Example. On Economic Problems, 2014,(06):121-125.

[5] Deng Xiaole. SWOT Analysis on Development of International Freight Forwarding Industry of Xinjiang under the Normal State. China Market, 2015,(16):131-133. 